\title{
Performance of Students in Computer Programming: Background, Field of Study and Learning Approach Paradigm
}

\author{
Prince Yaw Owusu \\ Amoako \\ Valley View University \\ P.O. Box AF 595 \\ Adentan-Accra, Ghana
}

\author{
Kofi Adu-Manu \\ Sarpong \\ Valley View University \\ P.O. Box AF 595 \\ Adentan-Accra, Ghana
}

\author{
John Kingsley Arthur \\ Valley View University \\ P.O. Box AF 595 \\ Adentan-Accra, Ghana
}

\author{
Charles Adjetey \\ Valley View University \\ P.O. Box AF 595 \\ Adentan-Accra, Ghana
}

\begin{abstract}
Many factors can be attributed to the high rate of failure in computer programming courses. This paper studies the background of students, their fields of study and learning approaches applied to the study of programming courses. It is worth considering as a major factor and necessary to research into the causes of failure of students in programming courses from the learner perspective. Programming courses form part of the core concentration areas for students especially studying Information Technology (IT) and Computer Science as well as those other fields of study sandwiched with IT in an undergraduate degree programs.
\end{abstract}

Through the use of questionnaires, interviews and focused group, a survey was conducted using one hundred (100) students at the middle and end of the semester. The responses from the three groups of students were compared. Their opinions to the usefulness of their background, field of study and learning approaches toward programming courses were investigated. The needs and concerns about these key factors are highlighted in the survey and discussed thereby leading to the inferences made and then proposed recommendations on the learning approach in relation to the background and field of study of students in computer programming courses in order to improve understanding of programming by students, hence, reducing failure rates.

\section{General Terms}

Information Technology, Computer Science, Sandwich, Programming courses,

\section{Keywords}

Computer programming, learning approach, influence on performance

\section{INTRODUCTION}

Programming is related to several fields of technology, and many university students are studying the basics of it. Unfortunately, they often face difficulties already on the basic courses [1]. It is necessary to obtain opinions on the difficulties in learning programming in order to support developing learning materials for basic programming courses. The difficulties have to be recognized to be able to aid learning programming in an effective way.

Practical programming is one of the basic skills pursued in computer science education. Within the discipline of computing success in learning to program has traditionally been attributed to presage factors. For example, participants undertaking the IBM Programmer's Aptitude Test (PAT) are asked to complete alphanumeric series, find matching figures and perform arithmetic reasoning. One trial of PAT included 63 American college students taking an introductory programming course [2].

A number of studies have attempted to identify factors contributing to success or failure in computer science studies, in order to identify members of the challenged cohort. Factors considered include: demographic profiles [3], mathematics capability [4], entry qualifications [5], prior experience of programming [6], [7], and self-efficacy and expectations of success [8].

We realize consideration of the background of the students which captures basic related dimensions, the field of which they are studying and their learning approach is worth researching.

\section{OBJECTIVES}

- To ascertain whether the background of students influence performance in computer programming.

- To find out the effect of field of study on performance of students in computer programming.

- To evaluate the learning approaches employed by students in studying computer programming.

- To determine whether students learning approach in studying programming influences their performance.

\section{PROBLEM STATEMENT}

It is quite alarming why most students of computer programming accomplish poorly in their performance. This has resulted in the phobia of many students studying IT related programmes in which they will be required to take computer programming course. There are many factors which can be considered to establish the causes of this failure. Considering the students background, field of study and their learning approach may be keen factors resulting to this quandary.

\section{LITERATURE REVIEW}

Teaching a programming language has long been a challenge in the classroom. The learning curve is a step function for many students; such students struggle to assimilate the concepts involved in the early stages, making little progress and becoming more and more confused, until, all of a sudden, 
the "penny drops". Overcoming this step is crucial; sadly, some students never make it, either failing or withdrawing [9].

Learning - the acquisition of new skills, knowledge, and capabilities always occurs within the context of human performance improvement [10].

Biggs describes a three stage model of learning: presage, process and product. Presage factors exist before the student enters the learning situation, and include such factors as prior knowledge, intelligent quotient, and home background. The process factors describe the learning context, which includes student perceptions. The product can be objective or subjective [9].

As harangue by [12] there are many reasons why students pass or fail particular subjects. It may be that the concept of a Programmer's Quotient is misdirected since (just as with IQ) innate cognitive ability is but one factor of many that affect student grades.

As cited by [13], according to [14] learning approaches have previously been considered in relation to a number of different subject disciplines, and high achieving students shown to be more likely to adopt a strategic approach to learning, and less inclined to adopt a surface apathetic approach.

Learning styles are considered to be intrinsic behaviors habitually applied by learners. Learning approaches describe tendencies: they are not immutable, nor are they independent of learning circumstance or environment. Nonetheless it is believed that "students also seem to develop habits in studying which may lead them to rely more on one or other approach" [15]. Learning approaches have been given less attention.

As established by [16], previous computer science coursework was not a significant indicator in predicting a student's potential success. However, he further claimed that prior knowledge of programming has a significant role in predicting academic success.

This may be related to influence of students course undertaken at the high school. In the same regard many institutions in Ghana consider science students from high school in the admission requirements to pursue programming inclusive programme at the university.

\section{METHODOLOGY}

This study employed a descriptive survey method. It was used to allow the researchers to vividly describe the background, the field of study and approach to study of students in programming language influence their performance. Survey was adopted for this study because to [17], it permits the researcher to summarise the characteristics of different groups or to measure their attitudes and opinions toward some issues.

The study was conducted among students of the Faculty of Science, Valley View University, Ghana. Specifically, students from level 100 to level 400 who have ever taken programming course participated in the survey. The participants voluntarily partake in the study.

A non-probabilistic sampling technique was used of which a purposive sampling method was used to gather the data for the study. This was implemented to achieve a convenient way for both participants and the researchers.

The instrument used for the data collection was closed-ended questionnaire which were directly administered to the participants. The adoption of this method is influenced by its popularity and research has shown that in case of big enquiries. It has been revealed that private individuals, research workers, private and public organizations and even governments have adopted this method [18]

Enquiries were made on the background of the students which included their age, gender, level at the university, programmes they are pursuing and programmes pursued at high school, and the number of times they have taken a particular programming course. These were related to their performance to ascertain whether they have influence. Other questions probed were "To what degree will you rank the performance of students in relation to their gender and field of study?" and "Which of the learning approaches are most effective for learning programming to increase knowledge acquisition and understanding?"

\section{RESULTS AND DISCUSSION}

Upon critical scrutiny of the answered questionnaire to ensure that responses were free from errors, further analysis were made using the Statistical Product and Service Solutions (SPSS) software, version 16.

In this section, we present discussions on the result obtained from the reactions of the respondents to the questionnaire distributed. Since a total of hundred (100) selected students were considered each figure obtained from the distributions represents the exact percentage.

Table 1: Frequency (\%) of Background of Respondents

\begin{tabular}{|c|c|c|c|c|c|c|c|c|c|c|c|}
\hline \multicolumn{2}{|c|}{ Gender } & \multicolumn{2}{|c|}{ Times taken } & \multicolumn{2}{|c|}{ Age } & \multicolumn{2}{|c|}{ Pursuing Programme } & \multicolumn{2}{|c|}{ Level in University } & \multicolumn{2}{|c|}{ High School Course } \\
\hline Male & 77 & Once & 63 & $15-20$ & 18 & Computer Science & 34 & $\begin{array}{l}\text { First Year } \\
\text { (Semester 2) }\end{array}$ & 26 & Science & 69 \\
\hline Female & 23 & Twice & 37 & $20-25$ & 69 & $\begin{array}{l}\text { Information } \\
\text { Technology }\end{array}$ & 62 & Second Year & 8 & Business & 5 \\
\hline & & & & Over 25 & 13 & Education with IT & 4 & Third Year & 13 & Arts & 25 \\
\hline & & & & & & & & Fourth Year & 53 & $\begin{array}{l}\text { Home } \\
\text { Economics }\end{array}$ & 1 \\
\hline
\end{tabular}


From Table 1 above, the outcome of the respondents with reference to their gender, number of times they have ever taken programming course and passed, age, programmes they are pursuing at the University, their level in the University and courses they offered at High School are shown.

It can be inferred that greater percentage of the respondents were males (73\% as against $23 \%$ ) implying that males are more into Computer or IT related programmes than females. With this most of them are between the ages of 20 and 25 and considerably less number of them between the ages of 15 and 20 , and over 25 years. Also, $62 \%$ depicting the highest percentage with respect to their programme at the university is
Information Technology, with $34 \%$ pursuing Computer Science and $4 \%$ taking Education with IT. With this most of them are in their fourth year (53\%) relating to the remaining $47 \%$ distributed among first year (who are in their second semester), third year and second year. With reference to the courses the students offered at the High School, the greater percentage $(69 \%)$ studied Science and the other $31 \%$ studied Arts, Business or Home Economics.

In critical relation to the research objectives, it can be deduced that significant number of students who take programming courses at the University do not always pass at the first sitting as substantiated by the $37 \%$ of the respondents taking it twice.

Table 2: Frequency (\%) of the Influence of Background and Field of Study

\begin{tabular}{|l|c|c|c|c|c|c|}
\hline $\begin{array}{c}\text { Level of Influence/ Background \& } \\
\text { Field of Study }\end{array}$ & $\begin{array}{c}\text { Below } \\
\text { age 25 }\end{array}$ & $\begin{array}{c}\text { Gender } \\
\text { dependence }\end{array}$ & $\begin{array}{c}\text { Level of } \\
\text { student }\end{array}$ & $\begin{array}{c}\text { No. of times } \\
\text { taken }\end{array}$ & $\begin{array}{c}\text { Field of } \\
\text { study }\end{array}$ & $\begin{array}{c}\text { High } \\
\text { School } \\
\text { course }\end{array}$ \\
\hline Strongly Agree & 20 & 11 & 13 & 24 & 22 \\
\hline Generally Agree & 33 & 23 & 40 & 35 & 20 \\
\hline Generally Disagree & 23 & 20 & 29 & 19 & 29 \\
\hline Strongly Disagree & 24 & 46 & 18 & 22 & 24 \\
\hline
\end{tabular}

With reference to Table 2 above, a consideration of the level of background and field of study influence on the performance of students in Computer programming courses is presented. It is clearly inferred that age is not a critical factor, and this is because the highest percentage seen to be $33 \%$ just agree generally and the remaining percentage distributed almost evenly to those who strongly agree, strongly disagree and generally disagree. Also, gender of the student is not much precarious to the students' performance which from above $46 \%$ strongly disagree that it has influence. The level of students is realized to be generally having influence on their performance with $40 \%$ agreeing generally to it and this adversely correlate with the number of times that they have taken the course and again draw a parallel with the field of study of the students. Irrespective of the course the student offered at High School does or does not clearly have influence on their performance in programming courses at the University as the distribution above is fairly made among those who agree or disagree ranging between $20 \%$ and $30 \%$.

Table 3: Frequency (\%) of the Degree of Performance, Influence of Gender and Field of Study

\begin{tabular}{|c|c|c|c|c|c|}
\hline Degree of Performance / Gender \& Field of Study & 1 & 2 & 3 & 4 & 5 \\
\hline Males degree of performance & 32 & 31 & 22 & 10 & 5 \\
\hline Females degree of performance & 9 & 21 & 50 & 16 & 4 \\
\hline Computer Science students degree of performance & 31 & 38 & 18 & 8 & 5 \\
\hline Information Technology students degree of performance & 19 & 33 & 34 & 12 & 2 \\
\hline Information Technology with Education students degree of performance & 10 & 21 & 37 & 26 & 6 \\
\hline
\end{tabular}
other discipline like education have average performance and

Respondents were required to rank the degree of performance of students in programming courses by 1 (highly comprehend) to 5 (least comprehend) in relation to the gender and field of study.

With regards to the field of study, Computer Science and Information Technology students are seen to have high degree of comprehension since from Table 3 about $85 \%$ of the respondents agree to that. Whereas students who combine this is substantiated with about $60 \%$ of respondent showing averagely comprehension of programming course.

Considering the outcome in Table 3 above, it is realized that males have high degree of performance in programming course since more than $60 \%$ of the respondents judged that males highly comprehend in the study of programming course and about $80 \%$ buttressing the point that females least comprehend.

Table 4: Correlation between Gender and Degree of Performance 


\begin{tabular}{|l|l|l|l|}
\hline \multicolumn{2}{|l|}{ Males degree of performance } & Females degree of performance \\
\hline Pearson Correlation & .150 & Pearson Correlation & .011 \\
\hline Sig. (2-tailed) & .138 & Sig. (2-tailed) & .910 \\
\hline N & 100 & N & 100 \\
\hline
\end{tabular}

To verify the relationship between the numeracy of male and female respondents to the degree of performance, Table 4 provides a correlation results. Since the Pearson Correlation value for male (.150) is not closer to zero and thus positive, it means that there is a strong relationship between the number of male respondents and their degree of performance. It is also clear that increase in the number of male respondents will increase the degree of performance of male in programming courses. Hence there is statistically significant correlation between number of male respondents and their degree of performance since the 2-tailed value (.138) is greater than .05 .

Although, the 2-tailed value of female respondents (.910) shows a statistically significant correlation between the number of female respondents and their degree of comprehension of programming course, on the contrary, there is a weak relationship (with Pearson Correlation value of $.011)$

Table 5: Learning Approach

\begin{tabular}{|l|c|c|c|c|c|c|c|}
\hline \multicolumn{1}{|c|}{ Learning Approach } & $\mathbf{1}$ & $\mathbf{2}$ & $\mathbf{3}$ & $\mathbf{4}$ & $\mathbf{5}$ & $\mathbf{6}$ & $\mathbf{7}$ \\
\hline Action Learning & 40 & 21 & 11 & 5 & 8 & 12 & 3 \\
\hline Collaborative Learning & 49 & 17 & 14 & 7 & 5 & 1 & 7 \\
\hline Creative Problem Solving & 43 & 16 & 18 & 8 & 9 & 2 & 4 \\
\hline Independent Learning & 13 & 9 & 12 & 18 & 17 & 11 & 20 \\
\hline Peer Assisted Learning & 28 & 31 & 16 & 7 & 9 & 7 & 2 \\
\hline Problem-Based Learning & 18 & 23 & 23 & 12 & 7 & 12 & 5 \\
\hline Enquiry-Based Learning & 12 & 13 & 20 & 14 & 12 & 9 & 20 \\
\hline
\end{tabular}

Table 5 provides the analysis of responses on learning approaches in order of effectiveness from 1 (highly effective) to 7 (least effective). The results obtained shows that Action Learning, Collaborative Learning, Creative Problem Solving, Peer Assisted Learning and Problem-Based Learning are highly effective learning approaches for resulting in high performance of students in programming courses. This is because more than $70 \%$ accepted them to be highly effective. Independent Learning and Enquiry-Based Learning are seen to be not highly effective for approaching the study of programming courses as can be inferred that about $50 \%$ agree that these approaches are least effective.

When the respondents were finally asked "if they have the opportunity to select a different course in place of programming whether they will choose other course over programming, 49\% said YES and 51\% said NO. This suffixes to say that only $2 \%$ difference of students who take programming courses are very much comfortable with programming courses.

\section{CONCLUSION}

It cannot be fairly conclusive that the background of student pursuing programming course is a major influence on performance although there is a significant correlation since majority of students who enrol in programmes in which programming courses are part and parcel of. The greater percentage of students who pursue computer programming related programmes are males as we found out from this research. This presupposes that males are presumed to have better performance.

Learning approaches that students adapt to the study of programming course is of greater importance with regards to their performance. In most cases, learning approach which requires practical and collaboration as well as persuading the learner to think outside the box and solve problem is much effective. It is therefore, worth stating that implementation of multiple approaches to learning programming courses will enhance high performance.

\section{ACKNOWLEDGMENTS}

We wish to acknowledge our referees for their profound and critical submissions. The immense support and guidance of Mr. Dominic Damoah, Head of Computer Science Department, Valley View University, cannot be overemphasized.

\section{REFERENCE}

[1] Essi Lahtinen, Kirsti Ala-Mutka, Hannu-Matti Jarvinen "A study of the difficulties of novice programmers", ITiCSE 
'05 Proceedings of the 10th annual SIGCSE conference on Innovation and technology in computer science education, pg 14-18, Vol. 37, September 2005

[2] Mazlack. L. (1980). Identifing Potential to Acquire Programming Skill. Communications of the ACAf, 23(1), 14-17.

[3] Rountree, N., Rountree, J., and Robins, A. (2002). Predictors of Success and Failure in a CS1 Course. ACM SIGCSE Bulletin 34, 4, 121-124.

[4] Boyle, R., Carter, J., and Clark, M. (2002). What makes them succeed? Entry, progression and graduation in Computer Science. Journal of Further \& Higher Education, 26, 1, 3-18.

[5] Alexander, S., Amillo, J., Boyle, R., Clark, M., Daniels, M., Laxer, C., Loose, K., and Shinners-Kennedy, D. Case Studies in Admissions to and Early Performance in Computer Science Degrees. ACM SIGCSE Bulletin, 35, 4 (December 2003), 137-147.

[6] Morrison, M. and Newman, T. S. (2001). A Study of the Impact of Student Background and Preparedness on Outcomes in CS1. ACM SIGCSE Bulletin, 33, 1, 179183.

[7] Ventura, P. (2005). Identifying Predictors of Success for an Objects- First CS1. Computer Science Education, 15, 3, 223- 243.

[8] John R. Maltby \& Jan Whittle (2000). Learning Programming Online: Student Perceptions and Performance

[9] Biggs J. (1978). Individual and Group Learning Difference Study Processe. British Journal of Educational Psychology, 48, 266-78.
[10] Ramalingam, V. and Wiedenbeck S. (1998). Development and Validation of Scores on a Computer Programming Self-Efficacy Scale and Group Analyses of Novice Programmer Self-Efficacy. Journal of Educational Computing Research, 19, 4, 367-381.

[12] De Raadt M., Hamilton M., Lister R. et. al., (2005) Approaches to Learning in Computer Programming Students and their Effect on Success, HERSA conference proceedings.

[13] Janet Hughes, D. Ramanee Peiris (2006). ASSISTing CS1 Students to Learn: Learning Approaches and Object-Oriented Programming, ITiCSE'06, June 26-28, 2006, Bologna, Italy.

[14] Byrne, M., Flood, B., and Willis, P. (2004). Using the Student Learning Framework to Explore the Variation in Academic Performance of European Business Students. Journal of Further \& Higher Education, 28, 1, 67-78.

[15] Wilson Learning Worldwide Inc, (2007). “Approach to Learning: How We Enhance Human Performance Through Learning" Position Paper.

[16] Wilson, B. (2002). A Study of Factors Promoting Success in Computer Science Including Gender Differences. Computer Science Education, 12, 141-164.

[17] Ary D., Jacobs L. C., \& Razavieh A. (2002). Introduction to Research in Education, $6^{\text {th }}$ Edition, Belmont: Wadsworth Thomas Learning.

[18] Kothari C. R. (2004), Research Methodology: Methods \& Techniques. New Delhi: New Age International Publishing

Limited 